\title{
An investigation of convective heat transfer in microchannel with
}

\section{Piranha Pin Fin}

\begin{abstract}
In this paper, we present an experimental and numerical study on a Piranha Pin Fin $(P P F)$ micro scale heat sinks. The PPFs were designed to enhance heat transfer by manipulating the flow field, selectively venting the fluid, and adding surface area. The hydraulic and thermal performances are studied for Reynolds numbers ranging from 508 to 2114 based on the channel hydraulic diameter. A conjugate convection/conduction heat transfer model was developed with COMSOL software, which showed good agreement to experiments. Velocity field and temperature distribution obtained from the model were also discussed to obtain a better understanding of the heat sink performance. Extraction effect was evaluated and analyzed. Friction factor and Nusselt number were obtained and compared with available correlations.
\end{abstract}

Key word: single-phase heat transfer; microchannel; Piranha Pin Fin.

\section{Introduction}

Microchannel heat sinks have been extensively studied because of their potential to meet the cooling requirement of high power density systems[1]. In recent years, with the increasing demand for dissipating high heat flux in MEMS and other systems, enhancement techniques at the micro scale have been receiving growing attention. Integrating pin fins into microchannels is a passive heat transfer control technique that enhances mixing[2] by disturbing the boundary layer development in addition to increased surface area. Prior efforts have been undertaken by several groups to extend fundamental knowledge pertinent to this technique[3-7].

Koşar and Peles [8] studied MEMS-based shrouded, staggered micro pin fin heat sink with de-ionized (DI) water. The pin fins were $243 \mu \mathrm{m}$ long with a hydraulic diameter of $99.5 \mu \mathrm{m}$. In their study, heat flux from $3.8 \mathrm{~W} / \mathrm{cm}^{2}$ to $167 \mathrm{~W} / \mathrm{cm}^{2}$ and Reynolds number from 14 to 112 were presented. Also, a comparison between experimental data and long tube correlations was made. Wang et al. [9] conducted an experimental study of heat transfer in microchannel with a single pillar and a few pillars with air for Reynolds number ranging from 100 to 5,600, and obtained Nusselt numbers ranging from 17.7 to 88.9. Micro particle image velocimetry ( $\mu$ PIV) was used to identify flow-mixing effect, and turbulent kinetic energy (TKE) was experimentally measured. This study shows that Nusselt number is strongly correlated with TKE. 
Colgan et al. [10] reported on a silicon microchannel cooler with optimized fin designs capable of dissipating heat fluxes of $400 \mathrm{~W} / \mathrm{cm}^{2}$ at an average surface temperature to liquid inlet temperature difference of $35^{\circ} \mathrm{C}$ with pressure drop less than $35 \mathrm{kPa}$. Xu et al. [11] designed a heat sink composed of parallel longitudinal microchannels and transverse microchannels in an attempt to separate the flow length into independent zones. They demonstrated an enhanced heat transfer accompanied with decreased pressure drop.

A new type of micro scale heat sinks, termed Piranha Pin Fin (PPF), shown in Fig. 1, was recently proposed by Woodcock et al. [12]. Besides adding surface area and enhancing mixing, this $P P F$ design is also able to extract and inject fluid. Heat flux dissipation of up to $700 \mathrm{~W} / \mathrm{cm}^{2}$ with dielectric fluid HFE-7000 was demonstrated. To gain insights into the PPF design and to develop optimal configuration and arrangement, a comprehensive single-phase study including experiments and modeling has been undertaken and is reported here. In addition, correlations based on dimensionless parameters, such as friction factor and Nusselt number, were developed and compared with existing ones.

\section{Experimental apparatus}

The experimental apparatus is depicted in Fig. 2. A helium tank connected to an HFE-7000 storage tank controls the system absolute pressure. To ensure the working fluid is maintained as liquid single phase, a system pressure above atmospheric was sustained during experiments. Inlet mass flow rate was measured by a Swagelok variable area flowmeter. Upstream and downstream pressures were measured through OMEGA ${ }^{\circledR}$ pressure transducers (PX 303) connected to the pressure ports shown in Fig.3 (a). T-type thermocouples were used to measure the fluid temperature upstream the inlet and downstream the exit. Average wall temperature was obtained by resistance temperature detectors (RTD) made of titanium and aluminum as discussed in [13]. Signals from the pressure transducer, multimeters, and thermocouples were recorded into a desktop computer through LABVIEW.

The device dimensions are shown in Fig.3. Each device had one inlet and multiple outlets. During operation a fraction of the fluid was extracted through the venting holes as discussed by Woodcock et al. [12] and by Yu et al. [13].

Fig.4 depicts the micro device package. The device was sealed and secured by a cover plate from the top and a set of O-rings placed in small grooves at the bottom for the inlet and outlet manifolds and pressure ports. Electrical probes were fixed at the bottom to provide contact to the heaters, which also served as a thermistor for average surface temperature measurements. 
Measurement uncertainties are listed in Table 1. Standard propagation of uncertainties method was used to obtain uncertainties of derived parameters [14].

\section{Modeling approach}

The main processes that were considered in the model were laminar flow, conduction heat transfer in the solid substrate, and convective heat transfer to the liquid. The governing equations include continuity (incompressible), momentum conservation, and energy conservation; all cases were modeled assuming stationary state:

$$
\begin{gathered}
\rho(u \cdot \nabla) u=\nabla \cdot\left[-p I+\mu\left(\nabla u+(\nabla u)^{T}\right)\right]+F \\
\nabla \cdot(\rho u)=0 \\
\rho c_{p} u \cdot \nabla T+\nabla \cdot q^{\prime \prime}=Q \\
q^{\prime \prime}=-k \nabla T
\end{gathered}
$$

Fig. 5 depicts the boundary conditions for the conjugate heat transfer model. All pertinent properties were saved as user-defined fluid.

\section{Data reduction}

The pressure drop was calculated between the two pressure ports, and the Reynolds number, $R e_{c h}$, was calculated based on the channel hydraulic diameter according to:

$$
\begin{aligned}
\Delta P & =P_{\text {in }}-P_{\text {out }} \\
\mathrm{Re}_{c h} & =\frac{G_{c h} d_{c h}}{\mu}
\end{aligned}
$$

Friction factor, $f$, was calculated through Eq. (7), where $L$ is the distance between the pressure ports:

$$
f=\frac{2 \Delta P}{\rho_{f} u_{i n}^{2}} \frac{d_{c h}}{L}
$$

The effective heat transfer coefficient, $h_{\text {eff }}$, and the effective Nusselt number, $N u_{e f f}$, were obtained similar to [13]:

$$
h_{e f f}=\frac{q_{e f f}^{\prime \prime}-q_{\text {loss }}^{\prime \prime}}{T_{w}-T_{b}}
$$




$$
N u_{e f f}=\frac{h_{e f f} d_{c h}}{k}
$$

To quantify the fluid extraction for each $P P F$ row, an extraction coefficient was defined according to:

$$
\alpha=\frac{N \dot{m}_{c h i m}}{\dot{m}_{\text {inlet }}}
$$

where $\dot{m}_{\text {chim }}$ is the mass flow rate for each $P P F$ and $N$ is the number of $P P F$ in a row. In the current study the PPFS were in staggered arrangement and $N$ was 4 or 5.

\section{Fluid flow in the PPFs}

\section{Results and Discussion}

Skin friction from the endwalls, skin friction from the pin fins' surface, and form friction caused by the disturbance of the velocity field contribute to the total pressure drop. When the pin fins' aspect ratio $(H / D)$ is large (more than 8 ), the pressure drop is dominated by the pin fins' surface - endwall friction is secondary [15]. For very short fins (smaller than $1 / 2$ ), endwall friction dominates the pressure drop. In this study, the pin fin's height-to-hydraulic diameter aspect ratio was 1.3. As a result, both endwall friction and the pin fins' surface contributed to the total pressure drop. Additionally, in contrast to studies with single outlet, the total pressure drop depends on the extraction coefficient. The pressure drops measured from experiments and modeling show good agreement (Fig. 6). For staggered pin fin arrangement, this trend was also observed by Kosar and Peles [15]. In the wake region around the PPF's tail, interaction between the fluid and the walls is more rigorous for high inlet velocity. Second order polynomial curve fit to the experiments and simulations is included in Fig. 6.

As expected, the pressure drop for the channel with PPFS was higher than that for a plain channel. Furthermore, the relative difference increased with inlet velocity. For both plain channel and PPF channel flow, 'normal inflow velocity' conditions were set. An entrance effect was observed, as shown in Fig. 7, but the flow became fully developed before reaching the $P P F$ arrays. A second order polynomial regression for pressure drop versus inlet velocity was developed for both geometries as shown below:

$$
\Delta P_{P P F}=0.9039 u_{i n}^{2}+1.7371 u_{i n}-0.2984
$$




$$
\Delta P_{\text {plainchannel }}=0.3731 u_{\text {in }}^{2}+1.7847 u_{\text {in }}-0.1228
$$

Friction factor for plain microchannel and microchannel with PPFs is shown in Fig. 8. Predictably, the friction factor decreased with Reynolds number for both cases. However, the friction factor for plain microchannel decreased more rapidly than that for microchannel with PPFs with increasing Reynolds number. The friction factor for the $P P F$ array was much lower than the prediction from most correlations developed for channels with pin fins shown in Fig. 8[16-18], but was reasonably well predicted by the Hagen-Poiseuille parallel plate correlations. This observation is linked to fluid extraction and the pressure distribution is depicted in Fig. 9. Although the PPFs in the microchannel add fiction and form drag, the streamlined design and the significant fluid extraction lead to a slight increase of the friction factor compared to a plain microchannel.

The channel flow was segregated and analyzed into three sections - from the inlet to the first $P P F$ row (traditional channel flow), the $P P F$ section, and downstream from the $P P F$ arrays. After entrance region of about 2.1 to 8.7 (depending on Reynolds number) hydraulic diameters, the cross-sectional velocity distribution was kept constant (Fig. 7), and the pressure decreased as a result of viscous effects (Fig. 9). Once the fluid reached the PPFs, extraction started. Generally speaking, the extraction coefficient, $\alpha$, decreased along the flow direction (Fig. 10), but because of the nature of staggered arrangements; it did not decrease at a constant rate. For example, the extraction coefficient of the second array increased because it had an additional $P P F$ and it faced the high velocity fluid from the wake region generated by the upstream pin fins. However, in the third array, the extraction coefficient dropped sharply as it returned to the configuration of the first array. The wake effect of the pin fins is apparent in the immediate region downstream from the PPF arrays. However, about 6.25 hydraulic diameters downstream, the flow was restored to the original channel flow.

The cross-sectional velocity distribution in the channel is depicted in Fig. 11 and Table (2) identifies pertinent cross-sectional positions. Positions $P 1$ and $P 2$ are located upstream the $P P F$ array where the fluid has not been disturbed and extracted. As no slip boundary conditions was applied, velocity at $Z / H=0$ and $Z / H=1$ (shown in Fig. 11(b)) was zero. The velocity increased until mid-plane where it peaked. For laminar flow in rectangular channel, Sparrow et al. [19] conducted experiments to study the entrance length with difference width-to-height aspect ratios. It was found that larger aspect ratio channels have shorter entrance lengths 
(Eqs. (13) and (14)). Comparison between $P 2\left(\frac{L_{e}}{D_{e} R e}=0.004125\right.$ at $\left.P 2\right)$ and $P 3$, the difference of the peak velocity magnitude in P1 and P2 is $0.3 \%$, suggesting the flow was fully developed. In this study, the aspect ratio was about 12 , and the entrance length is expected to be smaller than a channel with an aspect ratio of 5 (Eq. (13)).

$$
\begin{aligned}
& \frac{L_{e}}{D_{e} \operatorname{Re}}=0.0138 \text { for a } 5: 1 \text { channel } \\
& \frac{L_{e}}{D_{e} \operatorname{Re}}=0.0317 \text { for a } 2: 1 \text { channel }
\end{aligned}
$$

As fluid flow over the $P P F \mathrm{~s}$, a fraction of the fluid is extracted through the venting holes. As a result, the mid-plane velocity at $P 5$ and $P 6$ decreased compared to positions $P 1, P 2$, P3 and P4. Besides extraction, the $P P F$ also disturbs the fluid field leading to separation and mixing. This is apparent when considering the velocity distribution in the $Z$ direction where local minima are observed. Such minima were also observed by Rudyak and Andrey [20] who linked it to mixing in laminar flow. After passing through the $P P F$, a new velocity distribution is rebuilt and the velocity decreased to about half of the original velocity (i.e., upstream the first $P P F$ row).

\section{Heat transfer}

Fig. 12 and Fig. 13 depict the experimental and numerical results for the average heater temperature for Reynolds number of 982 and 2114, respectively. The experiments predicted the simulation within $10 \%$. The average heater temperature increased almost linearly with heat flux, which is expected as the heat transfer coefficient is independent of heat flux. However, the heat transfer coefficient depends on the Reynolds number, and as a result, the two curves have different slopes.

The temperature distributions in the device, $P P F$ arrays, and a single $P P F$ are shown in Fig. 14- Fig. 16. In the silicon substrate, because of heat conduction, the temperature upstream the $P P F$ array increased along the fluid direction until reaching the PPFs. From that point on, the fluid temperature increased at a much faster rate. It is observed that the highest temperature difference in the silicon base was more than $20^{\circ} \mathrm{C}$, which indicates a need for a material with a higher thermal conductivity than silicon for improved cooling.

The temperature distribution in the $P P F$ arrays and in a single $P P F$ are shown in Fig. 
15 and Fig. 16, respectively. In the vertical direction, heat is transferred from the bottom to the top; thus, the bottom surfaces were always hotter than the top surfaces. In the flow direction, it is observed that the first two arrays were much cooler than the downstream arrays because of the high extraction coefficient at these locations. At the same time, the coldest fluid that was removed through the venting holes also led to lower $P P F$ temperatures. For a single $P P F$, the leading edge facing the cold fluid holds the lower temperature. As the working fluid flows toward the trailing edge of the $P P F$, adverse pressure zone developed and the velocity decelerated. At the trailing edge, the solid structure still contributed to heat spreading. However, convection heat transfer was not as effective as it was in the leading edge, resulting in the highest temperature of the $P P F$ being at the trailing edge.

Because of conduction in the silicon, heat spread to the upstream region, and as a result, the silicon was hotter than the fluid. Since position $P 2$ is closer to the heat source, the solid temperature was much higher than at $P 1$ as shown in Fig. 17. In the $P P F$ array, the temperature monotonically decreased in the solid $(Z / H \geqslant 1)$, but the liquid phase experienced a small peak around $Z / H=0.7$ as demonstrated by positions $P 3$ and $P 4$. In contrast to $P 1$ and $P 2, P 3$ and $P 4$ were located downstream the $P P F$ array. Fluid around $P 5$ and $P 6$ was not only heated by the bottom wall, but also by the $P P F s^{\prime}$ surface. This can be attributed to the temperature peaks found in $P 5$ and $P 6$. In addition, from Fig. 11, it was found that there was a velocity valley in the middle of the channel at $P 5$ and $P 6$, which also contribute to the temperature peaks.

For thermally developing flow in parallel plate, Shah and London [21] proposed the correlations given by Eq. 15 for uniform heat flux boundary conditions, where $\mathrm{Nu}_{0-x}$ is the average Nusselt number from 0 to $x$ and $x_{*}=\frac{x / D_{h}}{R e P r}$. Fig. 18 shows the Nusselt number obtained from Eq. 17 and from the modeling for a plain channel. When calculating $\mathrm{Nu}_{0-x}$ with Eq. 15, $x$ was set to $2.5 \mathrm{~mm}$ in both the model and experiment. The discrepancy between the numerical results for a plain channel and Shah and London's correlation [21] for the Nusselt number ranged from $10 \%$ to $16 \%$. The difference is primarily attributed to heat spreading in the silicon, which is not captured by Shah and London's correlation, but was included in the model. Also, in both the modeling and experiment, only one side was heated at a uniform heat flux, but the correlation assumes that all sides are heated. 


$$
N u_{0-x}=\left\{\begin{array}{l}
2.236 x_{*}^{-1 / 3},\left(x_{*} \leq 0.001\right) \\
2.236 x_{*}^{-1 / 3}+0.9,\left(0.001<x_{*} \leq 0.01\right) \\
8.235+0.0364 / x_{*},\left(x_{*}>0.01\right)
\end{array}\right\} \text { for parallel plate }
$$

For thermally fully developed flow with uniform heat flux in ducts, the Nusselt number is not dependent on the Reynolds number. However, for thermally developing flow, it is a function of the Reynolds number. The entrance length increases with the Reynolds number. Also, for the same geometry and location, the local Nusselt number increases with Reynolds number. As a result, the average $\mathrm{Nu}_{0-x}$ is larger for higher Reynolds numbers. Eqs. 16-18 are power fit for $\mathrm{Nu}$ vs. Re for the microchannel with PPFs, a plain channel, and Shah and London's correlation, respectively.

$$
\begin{gathered}
N u_{P P F}=0.5683 \mathrm{Re}^{0.5842} \\
N u_{\text {plain }}=2.1219 \mathrm{Re}^{0.3204} \\
N u_{\text {Shah\&London }}=2.2348 \mathrm{Re}^{0.3333}
\end{gathered}
$$

Comparing Eq. 16 and Eq. 17 reveals that for the same Reynolds number, the microchannel with PPFs had a higher Nusslet number than for plain channel for Reynolds numbers larger than 147.5. Since the Nusselt number for PPFs is more dependent on the Reynolds number (i.e., the Reynolds number has a larger exponent in the correlation) the enhancement increases with Reynolds number. The increase is up to $86 \%$ for Reynolds number of 2114 .

\section{Conclusion}

Single-phase fluid flow and heat transfer in a microchannel with PPFs was experimentally and numerically studied. Friction factor and Nusselt number were obtained and used to evaluate the performance of the heat sink. Velocity field and temperature distributions obtained from modeling were shown and discussed. The unique extraction effect caused by the $P P F S^{\prime}$ ability to vent fluid was shown and extraction coefficient in difference arrays was obtained. The main conclusions drawn from this study are as follows:

1) Pressure drop and average surface temperature obtained from experiments and modeling matched well. This provided confidence for further in-depth analysis pertinent to the thermal and hydraulic performance of the $P P F$, such as velocity field and temperature distribution.

2) The friction factor is larger but still comparable with a plain channel. However, it is much smaller than the friction factor obtained from existing studies and correlations for pin fin heat sinks. 
3) The microchannel with PPFs enhances heat transfer in several ways. It provides additional area for heat spreading and interfacing with cold fluid. The extruded PPFs disturbed the velocity field, and separation and mixing further enhances heat transfer. Fluid extraction leads to a significant enhancement of the Nusselt number while reducing pressure drop.

None declared

\section{Conflict of interest}

\section{Acknowledgement}

Funding for this research is provided by DARPA through the ICECool Fundamentals program.

\section{NOMENCLATURE}

\begin{tabular}{|c|c|}
\hline$A_{h}$ & heater surface area, $\left[\mathrm{cm}^{2}\right]$ \\
\hline$c_{p}$ & liquid heat capacity, $\left[\mathrm{kJ} / \mathrm{kg} \cdot{ }^{\circ} \mathrm{C}\right]$ \\
\hline$d$ & hydraulic diameter, $[\mathrm{m}]$ \\
\hline$F$ & Body force \\
\hline$G$ & mass flux, $\left[\mathrm{kg} / \mathrm{m}^{2} \cdot \mathrm{s}\right]$ \\
\hline$h$ & heat transfer coefficient, $\left[\mathrm{W} / \mathrm{m}^{2} \cdot{ }^{\circ} \mathrm{C}\right]$ \\
\hline I & unit matrix \\
\hline$k$ & thermal conductivity, $\left[\mathrm{W} / \mathrm{m} \cdot{ }^{\circ} \mathrm{C}\right]$ \\
\hline$\dot{m}$ & mass flow rate of working fluid, $[\mathrm{kg} / \mathrm{s}]$ \\
\hline$P$ & pressure, $[\mathrm{Pa}]$ \\
\hline$q^{\prime \prime}$ & heat flux, $\left[\mathrm{W} / \mathrm{cm}^{2}\right]$ \\
\hline$R$ & heater resistance, $[\Omega]$ \\
\hline
\end{tabular}




\begin{tabular}{|c|c|}
\hline$T_{w}$ & wall temperature, $\left[{ }^{\circ} \mathrm{C}\right]$ \\
\hline$T_{\text {inlet }}$ & fluid inlet temperature, $\left[{ }^{\circ} \mathrm{C}\right]$ \\
\hline$T_{\text {outlet }}$ & fluid outlet temperature, $\left[{ }^{\circ} \mathrm{C}\right]$ \\
\hline$Q$ & heat source, $\left[\mathrm{W} / \mathrm{m}^{3}\right]$ \\
\hline$U$ & voltage, $[\mathrm{V}]$ \\
\hline $\mathrm{Nu}$ & Nusselt number \\
\hline$R e$ & Reynolds number \\
\hline$f$ & friction factor \\
\hline$q$ & Heat loss, $[\mathrm{kW}]$ \\
\hline \multicolumn{2}{|c|}{ Greek Symbols } \\
\hline$\alpha$ & density, $\left[\mathrm{kg} / \mathrm{m}^{3}\right]$ \\
\hline$\rho$ & surface enhancement ratio \\
\hline$\mu$ & \\
\hline \multicolumn{2}{|c|}{ Subscripts } \\
\hline$c h$ & channel \\
\hline chim & chimney \\
\hline eff & effective \\
\hline$w$ & wall \\
\hline bulk & fluid bulk average \\
\hline in & inlet \\
\hline
\end{tabular}




\begin{tabular}{|l|l|}
\hline$b y$ & bypass \\
\hline$e x$ & extraction \\
\hline$s p$ & single-phase \\
\hline
\end{tabular}

\section{References}

[1] S. G. Kandlikar, "History, Advances, and Challenges in Liquid Flow and Flow Boiling Heat Transfer in Microchannels: A Critical Review," J. Heat Transfer, vol. 134, no. 3, p. 034001, 2012.

[2] Y. Peles, A. Koşar, C. Mishra, C. J. Kuo, and B. Schneider, "Forced convective heat transfer across a pin fin micro heat sink," Int. J. Heat Mass Transf., vol. 48, no. 17, pp. 3615-3627, 2005.

[3] W. Qu and A. Siu-Ho, "Experimental study of saturated flow boiling heat transfer in an array of staggered micro-pin-fins," Int. J. Heat Mass Transf., vol. 52, no. 7-8, pp. 1853-1863, Mar. 2009.

[4] Y. Xue, M. Yuan, A. Ma, and J. Wei, "Enhanced Boiling Heat Transfer by Using Micro-Pin-Finned Surface in Three Different Test Systems," Heat Transf. Eng., vol. 32, no. 11-12, pp. 1062-1068, Oct. 2011.

[5] A. Bejan and A. Morega, "Optimal Arrays of Pin Fins and Plate Fins in Laminar Forced Convection," J. Heat Transfer, vol. 115, no. November, p. 75, 1993.

[6] R. W. Knight, J. S. Goodling, and D. J. Hall, "Optimal thermal design of forced convection heat sinks-analytical," J. Electron. Packag. Trans. ASME, vol. 113, no. 3,pp. 313-321, 1991.

[7] J. Li, G. P. Peterson, and P. Cheng, "Three-dimensional analysis of heat transfer in a micro-heat sink with single phase flow," Int. J. Heat Mass Transf., vol. 47, pp. 4215-4231, 2004. 
[8] A. Koșar and Y. Peles, "Thermal-Hydraulic Performance of MEMS-based Pin Fin Heat Sink," J. Heat Transfer, vol. 128, no. 2, p. 121, 2006.

[9] Y. Wang, F. Houshmand, D. Elcock, and Y. Peles, "Convective heat transfer and mixing enhancement in a microchannel with a pillar," Int. J. Heat Mass Transf., vol. 62, pp. 553-561, 2013.

[10] E. G. Colgan, B. Furman, M. Gaynes, W. Graham, N. Labianca, J. H. Magerlein, R. J. Polastre, and M. B. Rothwell, "A Practical Implementation of Silicon Microchannel Coolers for High Power Chips," in 21st IEEE SEMI-THERM Syposium, 2005.

[11] J. L. Xu, Y. H. Gan, D. C. Zhang, and X. H. Li, "Microscale heat transfer enhancement using thermal boundary layer redeveloping concept," Int. J. Heat Mass Transf., vol. 48, no. 9, pp. 1662-1674, Apr. 2005.

[12] C. Woodcock, X. Yu, J. Plawsky, and Y. Peles, "Piranha Pin Fin (PPF) Advanced flow boiling microstructures with low surface tension dielectric fluids," Int. J. Heat Mass Transf., vol. 90, pp. 591-604, 2015.

[13] X. Yu, C. Woodcock, Y. Wang, J. Plawsky, and Y. Peles, "A Study on Flow Boiling in Microchannel With Piranha Pin Fin," in InterPACK/ICNMM 2015, 2015, pp. V003T10A005-V003T10A005.

[14] R. J. Moffat, "Describing the uncertainties in experimental results," Exp. Therm. Fluid Sci., vol. 1, pp. 3-17, 1988.

[15] A. Koşar, C. Mishra, and Y. Peles, "Laminar Flow Across a Bank of Low Aspect Ratio Micro Pin Fins," J. Fluids Eng., vol. 127, no. May, p. 419, 2005.

[16] M. Jacob, "Discussion-Heat Transfer and Flow Resistance in Cross Flow of Gases Over Tube Banks,” in Mech. Eng. (Am. Soc. Mech. Eng.), 1938, pp. 381-392.

[17] W. B. Metzger, D. E., Fan, Z. N., and Shepard, "Pressure Loss and Heat Transfer 
Through Multiple Rows of Short Pin Fins," J. Heat Transfer, vol. 3, pp. 137-142, 1982.

[18] T. H. Chilton and R. P. Generaux, "Pressure Drop Across Tube Banks," Trans. Am. Inst. Chem. Eng., vol. 29, no. May. pp. 161-173, 1933.

[19] G. Sparrow, E. M., Hixon, C. W., and Shavit, "Experiments on Laminar Flow Development in Rectangular Ducts," ASME J. Basic Eng., vol. 89, pp. 115-123, 1967.

[20] Valery Rudyak and A. Minakov, "Modeling and Optimization of Y-Type Micromixers," Micromachines, vol. 33, no. 1, pp. 75-88, 2009.

[21] R. K. Shah and A. L. London, "Laminar Flow Forced Convection in Ducts: A Source Book for Compact Heat Exchanger Analytical Data," Acad. Press, p. 477, 1978. 